\title{
Article \\ Distinct Chemistries Define the Diverse Biological Effects of Plasma Activated Water Generated with Spark and Glow Plasma Discharges
}

\author{
Evanthia Tsoukou ${ }^{1}$, Maxime Delit ${ }^{1,2}$, Louise Treint ${ }^{1,2}$, Paula Bourke ${ }^{1,3,4}\left(\mathbb{D}\right.$ and Daniela Boehm ${ }^{1, *}$ \\ 1 Environmental Sustainability and Health Institute and School of Food Science and Environmental Health, \\ Technological University Dublin, D07 H6K8 Dublin, Ireland; evanthia.tsoukou@tudublin.ie (E.T.); \\ m.delit@hubebi.com (M.D.); 1.treint@hubebi.com (L.T.); paula.bourke@ucd.ie (P.B.) \\ 2 Ecole de Biologie Industrielle, 49 Avenue des Genottes, 95800 Cergy, France \\ 3 Plasma Research Group, School of Biosystems and Food Engineering, University College Dublin, \\ D04 V1W8 Dublin, Ireland \\ 4 School of Biological Sciences, Queens University Belfast, Belfast BT9 5DL, UK \\ * Correspondence: daniela.boehm@tudublin.ie
}

check for updates

Citation: Tsoukou, E.; Delit, M.; Treint, L.; Bourke, P.; Boehm, D. Distinct Chemistries Define the Diverse Biological Effects of Plasma Activated Water Generated with Spark and Glow Plasma Discharges. Appl. Sci. 2021, 11, 1178. https:// doi.org/10.3390/app11031178

Academic Editor: Emilio Martines Received: 21 December 2020

Accepted: 22 January 2021

Published: 27 January 2021

Publisher's Note: MDPI stays neutral with regard to jurisdictional claims in published maps and institutional affiliations.

Copyright: (c) 2021 by the authors Licensee MDPI, Basel, Switzerland. This article is an open access article distributed under the terms and conditions of the Creative Commons Attribution (CC BY) license (https:// creativecommons.org/licenses/by/ $4.0 /)$.

\begin{abstract}
The spread of multidrug-resistant bacteria poses a significant threat to human health. Plasma activated liquids (PAL) could be a promising alternative for microbial decontamination, where different PAL can possess diverse antimicrobial efficacies and cytotoxic profiles, depending on the range and concentration of their reactive chemical species. In this research, the biological activity of plasma activated water (PAW) on different biological targets including both microbiological and mammalian cells was investigated in vitro. The aim was to further an understanding of the specific role of distinct plasma reactive species, which is required to tailor plasma activated liquids for use in applications where high antimicrobial activity is required without adversely affecting the biology of eukaryotic cells. PAW was generated by glow and spark discharges, which provide selective generation of hydrogen peroxide, nitrite and nitrate in the liquid. The PAW made by either spark or glow discharges showed similar antimicrobial efficacy and stability of activity, despite the very different reactive oxygen species (ROS) and reactive nitrogen species profiles (RNS). However, different trends were observed for cytotoxic activities and effects on enzyme function, which were translated through the selective chemical species generation. These findings indicate very distinct mechanisms of action which may be exploited when tailoring plasma activated liquids to various applications. A remarkable stability to heat and pressure was noted for PAW generated with this set up, which broadens the application potential. These features also suggest that post plasma modifications and post generation stability can be harnessed as a further means of modulating the chemistry, activity and mode of delivery of plasma functionalised liquids. Overall, these results further understanding on how PAL generation may be tuned to provide candidate disinfectant agents for biomedical application or for bio-decontamination in diverse areas.
\end{abstract}

Keywords: plasma activated water; antibacterial efficacy; storability; temperature stability; cytotoxicity; enzymatic activity

\section{Introduction}

Cold plasma affects biological targets not only directly but also indirectly through the medium, which has broadened the potential applications of cold plasma in medicine [1]. Based on discharge type, working gas, and the chemical composition of the surrounding environment, various chemical reactions induced by plasma can be initiated, with a number of resulting primary and secondary reactive chemical species penetrating or dissolving into the aqueous environment [2]. After plasma treatment, these plasma activated solutions are enriched with reactive oxygen and reactive nitrogen chemical species with lifetimes ranging 
from seconds to months, making them useful for potential biomedical applications [3]. These types of solutions are known as PAL, plasma-treated liquids or plasma-functionalised liquids. The solution obtained after the plasma treatment acts as a bioactive solution which can be delivered to a target for specific biomedical applications such as cancer treatment, disinfection, and bio-decontamination, including places where direct plasma generation is less feasible or undesirable, such as cavities or body organs [4].

In order for PAL to be efficient for biomedical applications, the delivery of chemical species through plasma needs to be sufficient and successful. In the liquid phase, reactive species with a relatively long lifetime, such as hydrogen peroxide, nitrites, and nitrates, are produced by plasma-liquid interactions. In addition to these species, other potentially less stable reactive species with concentrations that vary depending on the target liquid solution type, are also important for their biological effects. Different PAL such as nonbuffered and buffered solutions may carry different concentrations of reactive chemical species and maintain diverse cytotoxic and antimicrobial properties [5] which can be retained for up to 18 months of storage at low temperatures [6]. Differences in reactive species chemistry and biological effect between various PAL can derive from different composition of the liquids, or antioxidants within the solutions as well as the plasma device and discharge conditions.

The search for novel techniques for improved microbial decontamination of environmental objects and surfaces in hospital rooms and healthcare facilities is currently the subject of a considerable number of investigations (e.g., UV light, hydrogen peroxide systems, ozone) [7]. Plasma treated solutions have been demonstrated to inactivate different bacteria, fungi and viruses [8-11]. PAL have been proposed as an alternative method of disinfection for medical devices such as duodenoscope reprocessing after current-standard manual cleaning [12] and as a novel mouthwash against oral pathogens [13].

The efficacy of each PAL depends on the reactive species produced in the PAL, the type of microorganism and phenotype [14]. PAL generated at atmospheric pressure will generally contain aqueous reactive species such as hydrogen peroxide, nitrite and nitrate ions, acidic $\mathrm{pH}$ values and a high oxidation reduction potential which may play a crucial role in the microbial inactivation potential of plasma activated water (PAW) $[3,15]$. Both reactive oxygen and reactive nitrogen species (ROS and RNS) in an acidic environment are important for the bactericidal activity $[3,16]$. The important role of peroxynitrite for a strong bactericidal effect has also been reported [17]. In terms of mechanism of antimicrobial action, PAW treatments can disrupt the outer and cytoplasmic membranes of bacteria, and be accompanied by leakage of intracellular components from the cells [3].

Plasma activated liquids have shown toxic effects not only on microorganisms, but also on the cells of higher organisms. Plasma generated reactive chemical species can cause mitochondrial dysfunction, caspase activation, cell cycle arrest, apoptosis, senescence or necrosis in mammalian cells [18]. Measuring the toxicity of these solutions in a model dependent manner, can provide helpful information as to whether or not PAL could be further used for antimicrobial activity on abiotic and biotic surfaces. A dominant function for $\mathrm{H}_{2} \mathrm{O}_{2}$ in the cytotoxic effects of PAL has been established [19] but, importantly, this compound is not the only chemical species that causes the cytotoxic effects. Girard et al. reported that hydrogen peroxide could not account alone for the toxicity in cell lines, but nitrites and hydrogen peroxide synergistically triggered cell death [20]. Peroxynitrous acid/ peroxynitrite can be generated by the interaction of nitrites and hydrogen peroxide [21,22] and can subsequently induce cell death by both cellular apoptosis and necrosis depending on the production rates and endogenous antioxidant levels [23].

The aim of this study is to assist the development of PAL as novel decontamination agents (for abiotic surfaces), and/or as antiseptic agents (for biotic surfaces, such as skin) which could be used as wound disinfectants, hand sanitisers or for washing at surgical sites. This study helps to build up an understanding of how plasma reactive species in liquid translate to different biological effects by employing two types of plasma activated water with very distinct ROS- and RNS-rich chemistries. Ideally, PAL should retain high level antimicrobial activity, but cause minimal or acceptable cytotoxicity in surrounding 
or exposed tissues. Plasma activated water, as the simplest form of a plasma activated liquid, generated using a spark (SD) and a glow (GD) cold atmospheric plasma discharge, respectively, was investigated for its antimicrobial properties on Gram-negative and Grampositive bacteria. The PAW was characterised in terms of its chemical composition and stability of the chemistry and antibacterial effect to a high temperature and pressure. The effect in other biological systems, namely the impact on mammalian cell growth and activity of the enzyme lactate dehydrogenase (LDH) were also determined. A significant finding of this work is the bactericidal stability of plasma activated water at different elevated temperatures and pressure, making heated PAW a novel disinfectant with a broad range of potential applications.

\section{Materials and Methods}

\subsection{Plasma System Setup and Sample Treatment}

Two different types of electrical discharge configuration have been set up for this plasma system [24]. In both setups, a stainless-steel needle served as the high voltage electrode and it was fixed perpendicular to the solution's surface. The distance between the high voltage needle tip and the liquid's surface was fixed to $5 \mathrm{~mm}$ for all experiments.

To realise two different discharge modes, the ground electrode connection was adjusted in two setups (Figure 1). In order to obtain the spark setup, the plastic petri dish was placed on a stainless-steel plate which was connected to the ground; in order to obtain the glow setup, a thin ground electrode rod was submerged into the water contained in the small petri dish. Both types of discharges were operated in atmospheric air. The maximum output voltage was $20 \mathrm{kV}$ with a variable frequency of 20-65 kHz depending on the plasma load capacitance. In this study a fixed frequency of $25 \mathrm{kHz}$ was used. Working power used was 16 Watt for glow discharge and 19 Watt for spark discharge. For the generation of PAW, $10 \mathrm{~mL}$ volume sterile deionised water was added into a plastic petri dish (55 mm inner dimeter), which corresponded to a water layer of about $4.2 \mathrm{~mm}$ depth. The power supply used for driving plasma discharges was a HV half bridge resonant inverter circuit (PVM500, INFORMATION UNLIMITED). The plasma activation times used to generate PAW were 5, 10, and 15 min. PAW samples were analysed directly after generation and stored at $4{ }^{\circ} \mathrm{C}$ in $15 \mathrm{~mL}$ tubes for analyses performed after 1 week. The temperature in both setups increased to a maximum $55^{\circ} \mathrm{C}$. After plasma treatment there was $1,1.9$, and $2.5 \mathrm{~mL}$ loss for SD5, SD10, and SD15 respectively and 1.3, 2.4, and $3.7 \mathrm{~mL}$ loss for GD5, GD10, GD15, respectively.

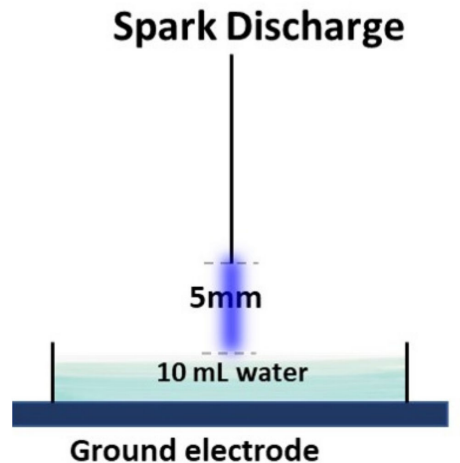

(A)

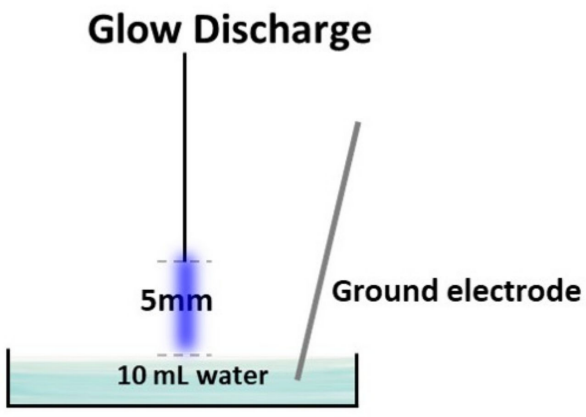

(B)

Figure 1. Schematic of air discharge in contact with water, (A) spark discharge; (B) glow discharge.

\subsection{Antimicrobial Efficacy}

\subsubsection{Bacterial Strains and Growth Conditions}

The bacterial strains Escherichia coli (E. coli) NCTC 12900 and Staphylococcus aureus (S. aureus) NCTC 1803 were obtained from the microbiology stock culture of the School of 
Food Science and Environmental Health of the Technological University Dublin, Ireland, and were maintained at $-80^{\circ} \mathrm{C}$ using protective beads (Technical Services Consultants Ltd., Heywood, UK). One protective bead of the selected strain was streaked onto tryptic soy agar (TSA, Biokar, France), incubated at $37^{\circ} \mathrm{C}$ for $24 \mathrm{~h}$ and further maintained at $4{ }^{\circ} \mathrm{C}$. A single colony of the culture was used to inoculate tryptic soy broth (TSB, ScharlauChemie, Spain) and incubated at $37^{\circ} \mathrm{C}$ for $18 \mathrm{~h}$.

\subsubsection{Preparation of Cell Suspensions}

The cells were harvested by centrifugation at 10,000 rpm for $5 \mathrm{~min}$, washed three times in PBS and finally resuspended in PBS. A total of $30 \mu \mathrm{L}$ of E. coli or $50 \mu \mathrm{L}$ of S. aureus suspension was diluted in 970 and $950 \mu \mathrm{L}$ of PBS, respectively, and these were the bacterial working inoculum. To determine each PAW's antimicrobial effect, 10\% bacterial suspension was added to $90 \%$ PAW and incubated at room temperature for 15, 30, 60 min or $24 \mathrm{~h}$ (PAW contact time). Untreated deionised water was used as control in all experiments and is shown as 0 min plasma activation time in the figures.

\subsubsection{Microbiological Analysis}

After each contact time, $30 \mu \mathrm{L}$ of a concentrated PBS $(4.5 \times$ PBS concentration) solution were added to the bacterial solution to neutralise the $\mathrm{pH}$ and precisely control contact times by stopping inactivation processes and cells were then diluted in Maximum Recovery Diluent (MRD; Merck, Ireland). Three decimal dilutions were made and $10 \mu \mathrm{L}$ aliquots were placed on TSA plates in triplicate. The plates were incubated aerobically at $37^{\circ} \mathrm{C}$ for $24 \mathrm{~h}$, after which colonies were counted to determine the number of viable cells. In order to detect any subsequent increase in visible colonies, the plates were further incubated for up to 2 days. Results obtained are represented as the surviving bacterial population in $\log _{10}$ colony forming unit $(\mathrm{CFU} / \mathrm{mL})$ with error bars representing standard deviation. Antimicrobial efficacy testing of PAW was performed on day 0 and 1 week post generation to determine the stability of the PAW.

\subsection{Investigation of the Chemical Composition of PAW}

\subsubsection{Quantification of Hydrogen Peroxide Using Titanium Oxysulfate}

Hydrogen peroxide concentrations were quantified employing the titanium oxysulfate ( $\mathrm{TiOSO}_{4}$, Sigma-Aldrich, Arklow, Ireland) colorimetric method by incubating $10 \mu \mathrm{L}$ $\mathrm{TiOSO}_{4}$ to $100 \mu \mathrm{L}$ of PAW in the dark for 10 min producing the yellow pertitanic acid. This absorbance was measured at $405 \mathrm{~nm}$ using a spectrophotometric microplate reader (MultiSkan GO, ThermoScientific, Waltham, MA, USA).

\subsubsection{Quantification of Peroxides Using Potassium Iodide}

Peroxide concentrations in PAW were determined by oxidation of potassium iodide to iodine and spectrophotometric measurement. In total, $50 \mu \mathrm{L}$ of PAL or standard curve samples were added to $50 \mu \mathrm{L}$ of phosphate buffer $(\mathrm{PB})$ solution $(10 \mathrm{mM})$ (buffered KI method) or deionised water (nonbuffered KI method) and $100 \mu \mathrm{L} 1 \mathrm{M}$ potassium iodide (SigmaAldrich, Arklow, Ireland) in a 96-well microtiter plate at room temperature, incubated for $20 \mathrm{~min}$ and the absorbance was read at $390 \mathrm{~nm}$ [19].

\subsubsection{Determination of Nitrite and Nitrate}

Concentration of nitrites was determined using Griess reagent (Sigma-Aldrich, Arklow, Ireland). A total of $50 \mu \mathrm{L}$ of Griess reagent was added to $50 \mu \mathrm{L}$ of PAW/standard curve sample and absorbance was read at $548 \mathrm{~nm}$, after $30 \mathrm{~min}$ of incubation. Nitrate concentrations were determined photometrically by using the Spectroquant ${ }^{\circledR}$ nitrate assay kit (Merck Chemicals, Darmstadt, Germany) adapted to a 96-well plate format, as described in [6]. 


\subsection{4. $\mathrm{pH}$ and Conductivity Measurements}

The $\mathrm{pH}$ of PAW was measured by an Orion $\mathrm{pH}$ meter (model 420A, Thermo Electron Corporation, Waltham, MA, USA) and conductivity measurements after plasma treatment of the solutions by a Jenway conductivity meter (model 4520, Jenway, UK).

\subsection{Effect of Elevated Temperature on PAW Stability \\ PAW Heated to Supra-Ambient Temperatures}

PAW samples were heated to $100{ }^{\circ} \mathrm{C}$ in a boiling water bath over a Bunsen burner for 5,10 , or $15 \mathrm{~min}$. PAW samples of $2.5 \mathrm{~mL}$ were placed in $15 \mathrm{~mL}$ sterile tubes and heated while the tubes were closed, to avoid loss of liquid due to high temperature. After each heating time, the samples were placed on ice for $5 \mathrm{~min}$ to halt any thermal effects.

PAW samples were autoclaved for $20 \mathrm{~min}$ at $121^{\circ} \mathrm{C} / 15$ pounds per square inch (psi) in an autoclave (MP25, Rodwell Scientific Instruments, Basildon, UK). A control sample was stored at room temperature. After cooling, all samples were stored at room temperature prior to chemical and antimicrobial assays.

\subsection{Mammalian Cell Culture}

\subsubsection{Eukaryotic Cell Lines}

The cytotoxicity of PAW was examined using the hamster ovarian cell line (CHO-K1) and the immortal human keratinocyte $(\mathrm{HaCaT})$ cell line, which were cultured according to [25]. For cytotoxicity assays, $20 \mu \mathrm{L}$ of cells were supplemented with $60 \mu \mathrm{L}$ of DMEM-F12 (D6421, Sigma-Aldrich, Arklow, Ireland), containing $2 \mathrm{mM} \mathrm{L-glutamine}+10 \%$ FBS (both Sigma-Aldrich, Arklow, Ireland), and $20 \mu \mathrm{L}$ of PAW or $20 \mu \mathrm{L}$ of untreated sterile deionised water (control) with a final cell concentration of $2.5 \times 10^{4}$ cells $/ \mathrm{mL}$. Cells were incubated at $37^{\circ} \mathrm{C}$ and $5 \% \mathrm{CO}_{2}$ in a humidified incubator for 2 days and cell growth was assessed.

\subsubsection{Analysis of Cytotoxicity}

Cell growth was assessed by crystal violet colorimetric growth assay in a 96-well plate. The culture supernatant was aspirated, and adherent cells were fixed with 70\% methanol (Sigma-Aldrich, Arklow, Ireland) for $1 \mathrm{~min}$. The methanol solution was then removed and cells were stained with $0.2 \%$ crystal violet solution (Sigma-Aldrich, Arklow, Ireland) for $10 \mathrm{~min}$. Excess stain was rinsed off with tap water, plates were air-dried, and the dye bound to the adherent cells was resolubilised with 10\% acetic acid (Sigma-Aldrich, Arklow, Ireland) and absorbance was measured at $600 \mathrm{~nm}$ using a spectrophotometric microplate reader (ThermoScientific, Waltham, MA, USA). Cell growth was expressed as percentage of control cells [19].

\subsection{LDH Activity Assay}

LDH activity was analysed using a commercial LDH activity kit (MAK066, SigmaAldrich, Arklow, Ireland) and L-lactic dehydrogenase from rabbit muscle (L2500, SigmaAldrich, Arklow, Ireland) dissolved in PBS. In brief, $10 \mu \mathrm{L}$ of LDH solution were mixed with $890 \mu \mathrm{L}$ of the respective PAW and $100 \mu \mathrm{L} 10 \times$ PBS to achieve neutralisation of the $\mathrm{pH}$. In total, $50 \mu \mathrm{L}$ of PAW mixture were incubated with $50 \mu \mathrm{L}$ of nicotinamide adenine dinucleotide (NAD) substrate mix and reduced nicotinamide adenine dinucleotide (NADH) standards were prepared according to the manufacturer's instructions. Time courses of NADH generation were taken every $5 \mathrm{~min}$ at $450 \mathrm{~nm}$ on a microplate reader with incubation at $37^{\circ} \mathrm{C}$, LDH activity was calculated according to

$$
\frac{B}{(\text { Reaction time }) \times V} \times \text { sample dilution factor }
$$

where $B$ was the amount of NADH generated between $t_{\text {initial }}$ and $t_{\text {final }}$ as determined using the NADH standard curve; reaction time was the time between $t_{\text {initial }}$ and $t_{\text {final }}$ (minutes) and $V$ was the sample volume added to well (mL). 


\subsection{Statistical Analysis}

Results are presented as means of three independent experiments with standard deviations using GraphPad Prism (GraphPad Software Inc., San Diego, CA, USA) or presented as individual experiments. Comparisons between different groups were analysed by one way or two way Analysis of Variance (ANOVA) with Bonferroni post test at $\alpha=0.05$.

\section{Results}

\subsection{Chemical Composition of PAW}

Water samples were plasma treated for 5,10 , or $15 \mathrm{~min}$ in atmospheric air to generate a range of PAW. The PAW were chemically characterised immediately after plasma treatment (Day 0) and 7 days (week 1) post generation. The $\mathrm{pH}$ of both types of PAW decreased, from neutral to acidic, to levels of 3.03 and 2.7 after 5 min exposure to plasma for spark discharge (SD) PAW and glow discharge (GD) PAW, respectively, and remained stable after 1 week of storage. There was little further decrease with additional treatment time up to $15 \mathrm{~min}$ (Figure 2A). The conductivity of SD and GD PAW increased with plasma treatment time, up to $2800 \mu \mathrm{S}$ for both types of PAW and remained stable after 1 week (Figure 2B).

Hydrogen peroxide was only detectable for SD PAW and not for GD PAW. Measurements on the day of PAW generation showed that $\mathrm{H}_{2} \mathrm{O}_{2}$ for SD PAW plasma treated for $10 \mathrm{~min}$ increased up to approximately $1500 \mu \mathrm{M}$ and after $15 \mathrm{~min}$ plasma treatment, the concentration plot seemed to approach a plateau (Figure 2C). Similar concentrations of peroxides (measured by KI with phosphate buffer or water) for the same samples of SD PAW were measured on Day 0, indicating that the peroxide was almost exclusively hydrogen peroxide (Figure 2D,E). After 1 week, hydrogen peroxide and overall peroxide concentrations remained at comparable levels for most SD PAW samples. As previously reported for this plasma set-up, no hydrogen peroxide was detectable in GD PAW by $\mathrm{TiOSO}_{4}$, but reaction with potassium iodide indicated the presence of other peroxides/oxidative species. After treatment for $5 \mathrm{~min}$ no detectable concentration of peroxides was observed, whereas $938 \mu \mathrm{M}$ of peroxides were detected after $15 \mathrm{~min}$ exposure to plasma (Figure 2D). After 1 week of storage, GD PAW 10 and 15 had lost more than half of the peroxide concentration compared to Day 0 (Figure 2D). Concentrations of peroxides were also measured by KI with addition of water instead of phosphate buffer solution in order to measure peroxides in nonbuffered environment (Figure 2E). Comparison between Figure 2D,E shows that SD PAW concentrations of peroxides in buffered and nonbuffered conditions were similar, whereas GD PAW measured by KI with water had about three times higher concentration of peroxides than KI with phosphate buffer solution. This indicates that there is a higher amount of oxidative species in nonbuffered GD PAW and suggests that neutralisation of the $\mathrm{pH}$ by phosphate buffer leads to loss of some plasma reactive species. After 1 week of storage, both measurements showed substantial peroxide loss for GD PAW.

Nitrites were only detected for GD PAW with concentrations up to $254 \mu \mathrm{M}$ for GD PAW 15 min (Day 0) (Figure 2F). Measurements after 1 week showed that nitrite had decreased for all GD PAW samples $(50 \mu \mathrm{M})$. Nitrate concentrations increased in both SD PAW and GD PAW with plasma activation time up to 5.9 and $6.7 \mathrm{mM}$, respectively, and after 1 week, no significant change in concentration of nitrates was observed for all PAW (Figure 2G). 
A

pH

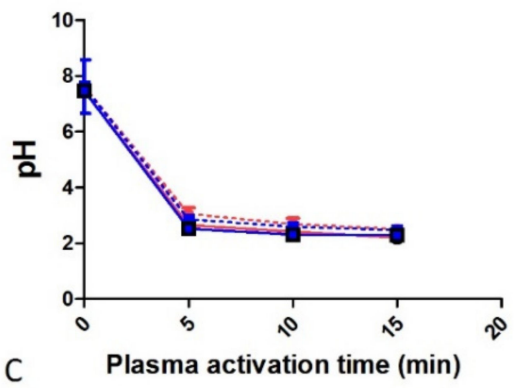

$\mathrm{H}_{2} \mathrm{O}_{2}$

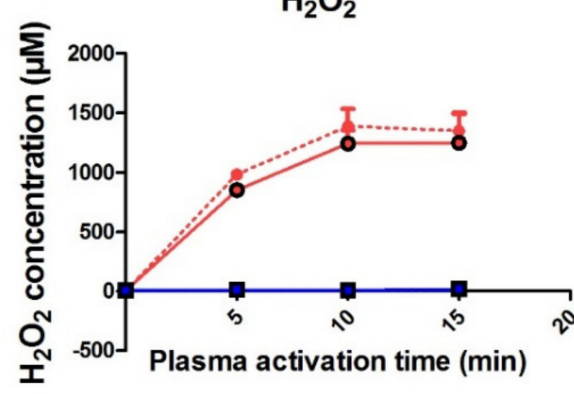

E
B

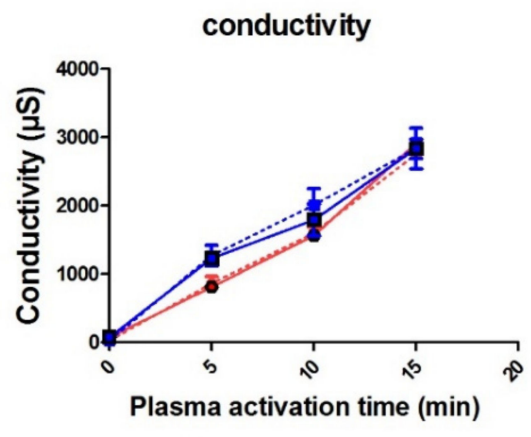

D

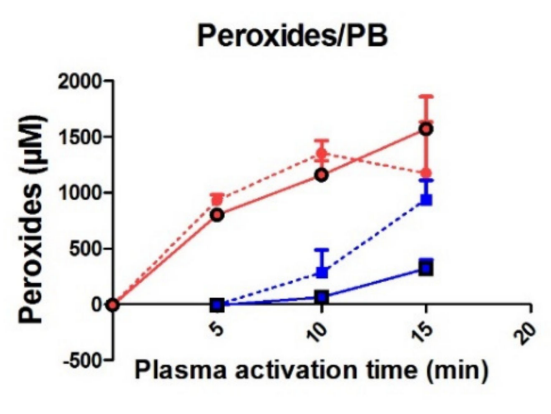

F

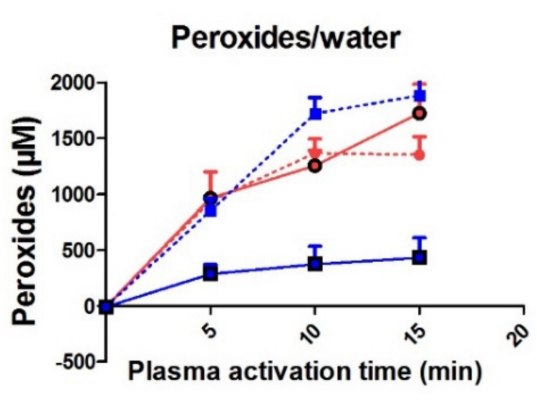

G
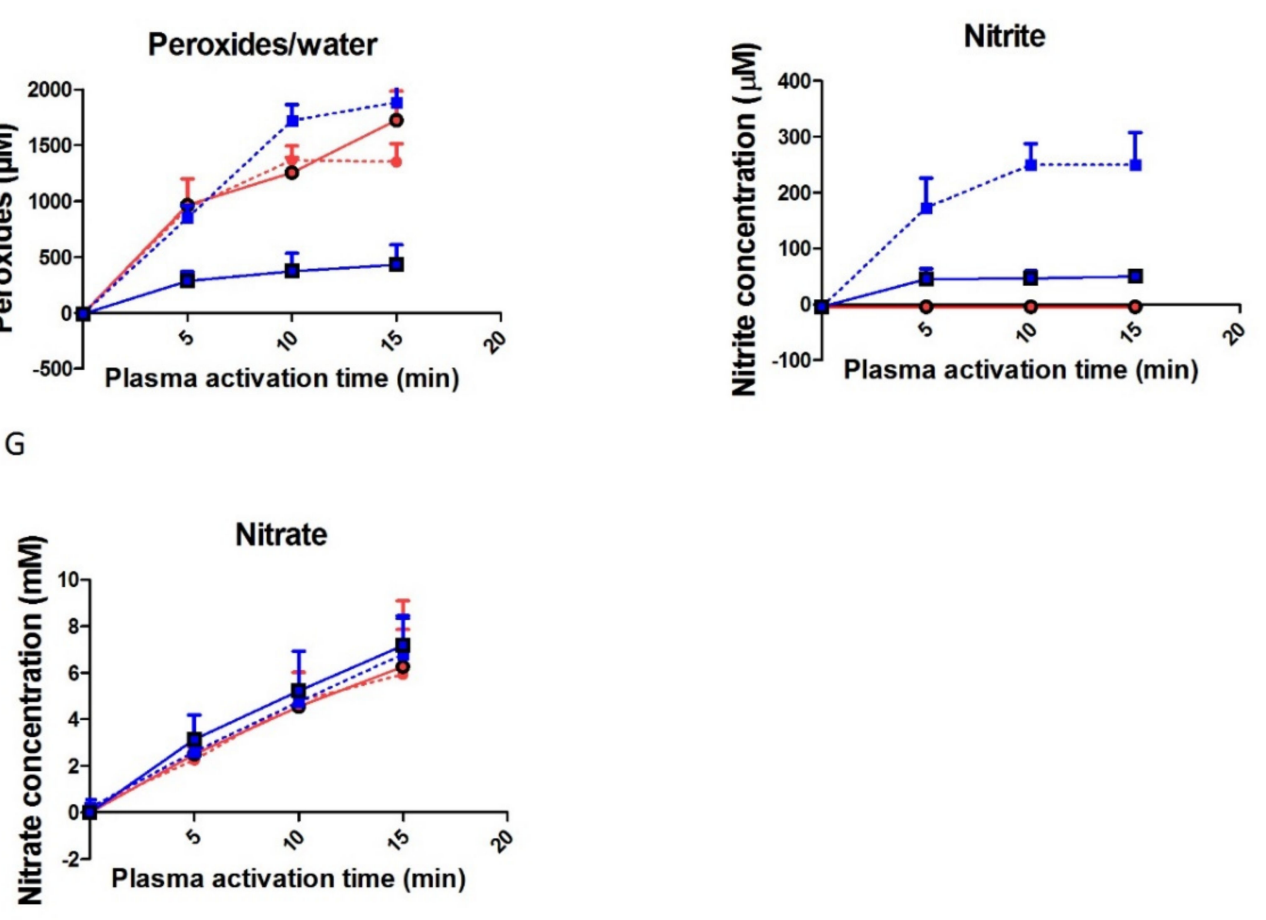
- SD PAW day 0
- SD PAW week 1
- GD PAW day 0
GD PAW week 1

Figure 2. Chemical composition of plasma activated water (PAW) made by spark and glow discharges on the day of generation (Day 0) and after 1 week storage. (A) $\mathrm{pH}$; (B) conductivity measurements; (C) hydrogen peroxide measured by $\mathrm{TiOSO}_{4}$; (D) peroxides measured by KI buffered with PB; (E) peroxides measured by KI and water; (F) nitrite concentration; (G) nitrate concentration (data shown as mean $\pm \mathrm{SD}, n=3$ experiments with measurements performed in triplicate). 


\subsection{Bactericidal Efficacy}

The bactericidal effects of PAW were tested against Gram-negative E. coli and Grampositive S. aureus strains using four different contact times: 15, 30, $60 \mathrm{~min}$ and $24 \mathrm{~h}$ (Figure 3). Generally, by increasing contact time, higher bactericidal activity was observed. Specifically, 15 min contact time was able to reduce $E$. coli concentrations by approximately $4 \log$ when incubated with GD PAW plasma treated for $15 \mathrm{~min}$ but showed very little effect on S. aureus (Figure 3A,B). S. aureus was less susceptible, even after $30 \mathrm{~min}$ of contact time, whereas E. coli was inactivated below the limit of detection $(\log 2 \mathrm{CFU} / \mathrm{mL})$, when incubated with SD PAW 15min, GD PAW 5, 10, and 15 min at 30 min contact time (Figure 3C,D). Increasing contact time to $60 \mathrm{~min}$ increased inactivation efficacy. E. coli was reduced by $6 \log$ by all PAW generated for longer than $10 \mathrm{~min}$, whereas only GD PAW generated for $15 \mathrm{~min}$ was able to cause $6 \log$ reduction for S. aureus (Figure 3E,F), and only on prolonged contact. The $24 \mathrm{~h}$ contact time reduced bacteria below the detection limit (approximately $6 \mathrm{log}$ reduction) for all PAW generation times (Figure 3G,H; SD (red lines) not distinguishable due to overlay of GD (blue lines)), whereas untreated control water (plasma activation time $0 \mathrm{~min}$ ) showed no effect on microbial survival even after $24 \mathrm{~h}$.

Comparison of PAW generated with the different discharge modes, showed that overall GD PAW was more efficient than SD PAW in reducing microbial counts for E. coli but showed no difference for $S$. aureus at shorter contact times, and increased antimicrobial efficacy of GD10 and GD15 was observed with extended contact time only.

In Figure 4, the bactericidal stability of PAW after 1 week is presented. For these experiments only 30 and 60 min contact times were investigated. After 1 week of storage, the bactericidal activity of PAW had decreased and none of the PAW samples were able to reduce $S$. aureus to undetectable levels (Figure 4B,D). Only the solutions plasma treated for $15 \mathrm{~min}$ retained the functionality to cause $4 \log$ and $6 \log$ reductions for E. coli, respectively, after $30 \mathrm{~min}$ contact time. Prolonging contact time to $60 \mathrm{~min}$ did enhance antimicrobial efficacy, indicating that the bactericidal activity of the liquids was reduced but not completely lost after the storage time.

\subsection{Heat Stability of Plasma Activated Water}

High stability of the bactericidal activity of PAW at supra-ambient temperatures was recorded. Both SD15 and GD15 PAW heated to between 50 and $100{ }^{\circ} \mathrm{C}$ for 5 min retained the ability to reduce bacterial concentrations below the limit of detection (data not shown). Similar peroxide concentrations were recorded between the heated and nonheated PAW. There were no adverse effects of heating SD15 and GD15 PAW at $100{ }^{\circ} \mathrm{C}$ for different time periods $(5,10$, or $15 \mathrm{~min})$ on the retention of antimicrobial efficacy (Figure 5A). Hydrogen peroxide concentration of SD PAW was observed to be relatively stable, for the different heating times (Figure 5B). Peroxide concentration was similar to that of hydrogen peroxide for SD PAW, indicating that the peroxides present are almost exclusively hydrogen peroxide (Figure 5B). Regarding GD PAW, hydrogen peroxide was not detected, but the concentration of peroxides indicated similar amounts as measured in SD PAW, which decreased slightly as the heating times increased. However, in nonbuffered conditions, an increase in peroxides was found (Figure 5B). 

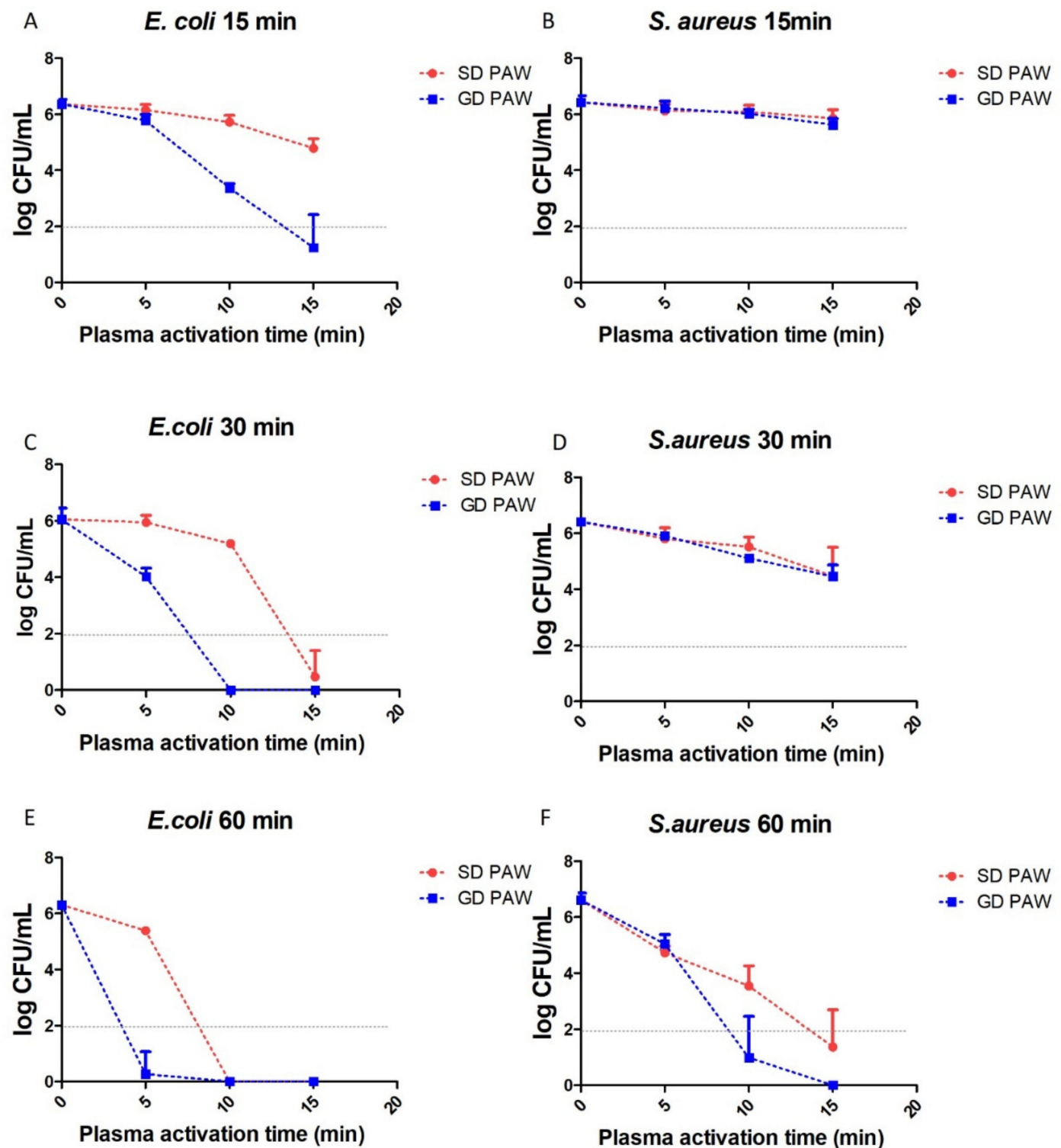

$\mathrm{F} \quad$ S.aureus $60 \mathrm{~min}$
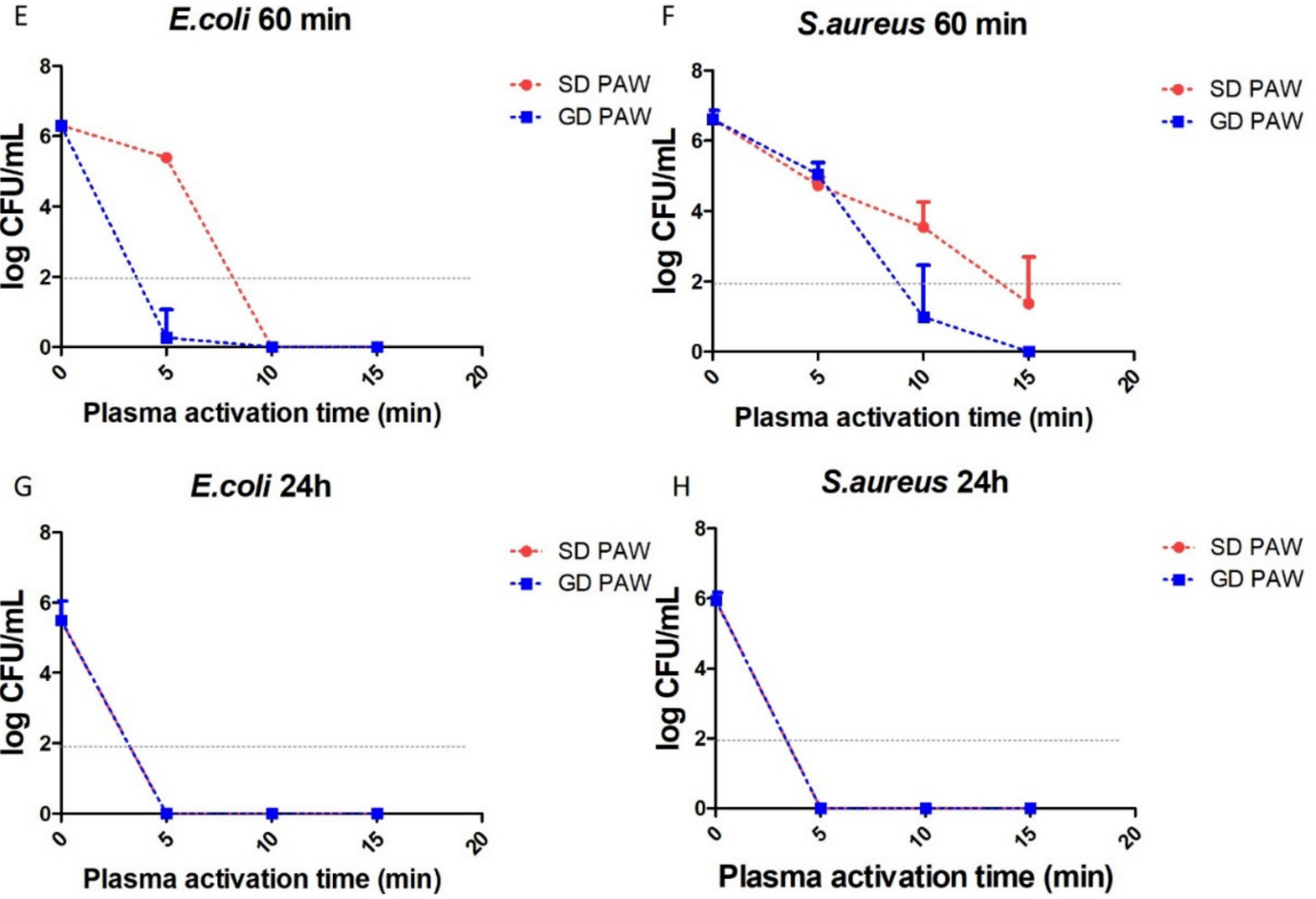

Figure 3. Bactericidal effects of PAW after 5, 10, or 15 min plasma activation, made by spark and glow discharges, on Escherichia coli (E. coli) and Staphylococcus aureus (S. aureus) with contact times of 15, 30, 60 min and 24 h on the day of PAW generation. (A) E. coli-15 min; (B) S. aureus-15 min; (C) E. coli-30 min; (D) S. aureus-30 min; (E) E. coli-60 min; (F) S. aureus $-60 \mathrm{~min} ;(\mathrm{G})$ E. coli-24 h; (H) S. aureus $24 \mathrm{~h}$ (data shown as mean $\pm \mathrm{SD}$, average of three experiments). Limit of detection: $2 \log _{10} \mathrm{CFU} / \mathrm{mL}$. 
A

\section{E.coli $30 \mathrm{~min}$}

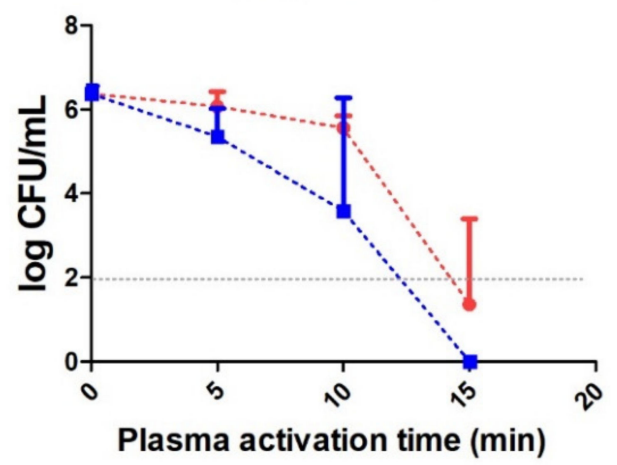

C

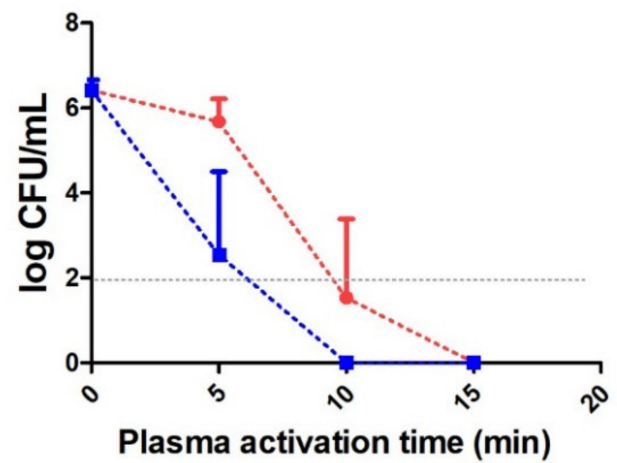

B

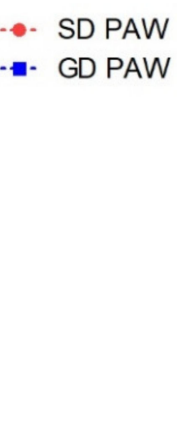

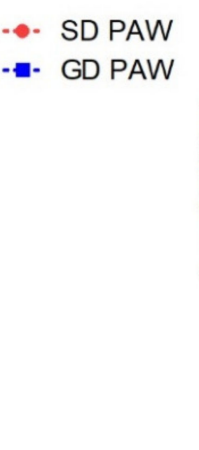

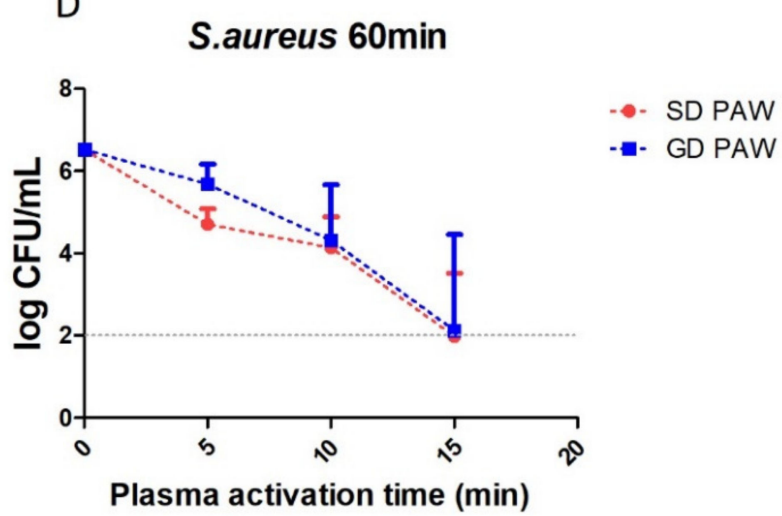

Figure 4. Bactericidal stability of PAW after 5, 10, or 15 min plasma activation, made by spark and glow discharges on E. coli and S. aureus with 30 and $60 \mathrm{~min}$ contact time a week after PAW generation. (A) E. coli-30 min; (B) S. aureus-30 min; (C) E. coli-60 min; (D) S. aureus $-60 \mathrm{~min}$ (data shown as mean \pm SD, average of three experiments). Limit of detection: 2 log 10 $\mathrm{CFU} / \mathrm{mL}$.

A

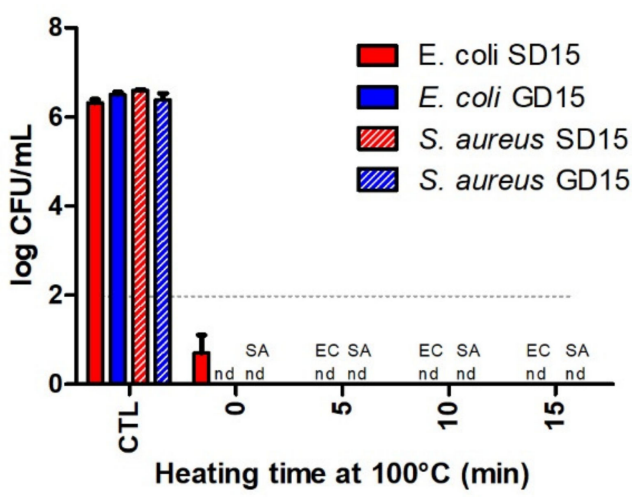

B

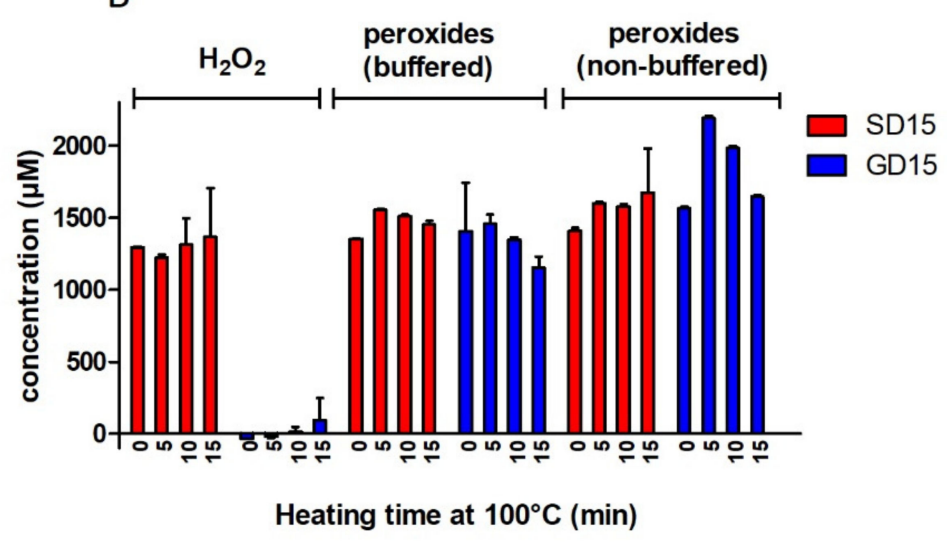

Figure 5. Effect of heating at $100{ }^{\circ} \mathrm{C}$ and heating time duration on retention of antimicrobial efficacy of PAW (SD15, GD15). (A) Bactericidal effects after 60 min contact time. (B) Chemical composition of hydrogen peroxide measured by $\mathrm{TiOSO}_{4}$, peroxides measured by buffered KI and nonbuffered KI. Data shown as mean $\pm \mathrm{SD}$; nd = no colonies detected. Limit of detection: $2 \log _{10} \mathrm{CFU} / \mathrm{mL}$. Controls (CTL) consisted of bacterial suspension exposed to untreated deionised water under the same conditions. 
Based on the high temperature stability observed at $100{ }^{\circ} \mathrm{C}$, PAW samples were further heat treated by autoclaving at $121^{\circ} \mathrm{C}, 15$ psi for $20 \mathrm{~min}$ and their chemical composition and antibacterial effects analysed. The liquids showed remarkable stability to high temperature and pressure in terms of their bactericidal activity. Autoclaved samples of SD15 showed comparable or even enhanced antibacterial activity to the original PAW for all contact times (Figure 6). Autoclaved PAW GD15 on the other hand retained a similar ability to reduce E. coli and S. aureus in some cases, but demonstrated reduced antibacterial efficacy in others. Analysis of hydrogen peroxide and other peroxides in these samples indicated a strong reduction in the concentrations of these species but the extent of reduction varied significantly between the 3 sets of PAW analysed (Table 1). The stark differences in concentrations of hydrogen peroxides and other peroxides between all three sets after autoclaving (despite similar initial concentrations in sets 1 and 2) cannot be explained at present. However, while the autoclave run itself was fixed at $20 \mathrm{~min}$, the heating and cooling phase were not precisely controlled in these experiments and may have varied depending on the initial temperature of the autoclave and the overall load. It is perceivable that extended holding times at elevated temperatures may allow chemical reactions/degradation processes to progress and therefore cause a greater reduction in peroxides and $\mathrm{H}_{2} \mathrm{O}_{2}$ than in cases where cooling proceeded more quickly.

\subsection{Cytotoxic Effects of PAW}

Incubation of CHO-K1 and HaCaT cells with 20\% PAW, demonstrated that both types of PAW possessed cytotoxic effects, with SD PAW exhibiting higher cytotoxicity than GD PAW for both cell lines under the same conditions. Specifically, SD 5 PAW resulted in approximately $90 \%$ cell inhibition for both cell lines tested and extending PAW generation time to 10 and 15 min led to complete cell growth inhibition (Figure 7A,B). In contrast, for GD PAW there was no direct correlation with plasma activation time observed and a minimum of $66-74 \%$ cell growth was maintained for both cell lines.

Table 1. Chemical composition of SD15 and GD15 PAW, before and after autoclaving. ND = not detected. Sets 1 and 2 correspond to sets 1 and 2 in Figure 6, set 4 is an additional set (data shown as mean \pm SD).

\begin{tabular}{cccccccc}
\hline & & $\begin{array}{c}\mathbf{H}_{\mathbf{2}} \mathbf{O}_{\mathbf{2}} \\
(\boldsymbol{\mu M})\end{array}$ & & \multicolumn{2}{c}{$\begin{array}{c}\text { Peroxides (Buffered) } \\
(\boldsymbol{\mu M})\end{array}$} & \multicolumn{2}{c}{$\begin{array}{c}\text { Peroxides (Nonbuffered) } \\
(\boldsymbol{\mu M})\end{array}$} \\
\hline & SD15 & SD15 & SD15 & SD15 & SD15 & SD15 \\
& $1150 \pm 12$ & $78 \pm 2$ & $1235 \pm 3$ & $92 \pm 2$ & $1269 \pm 56$ & $99 \pm 6$ \\
\hline Set 1 & $1064 \pm 16$ & $774 \pm 6$ & $1121 \pm 10$ & $850 \pm 2$ & $1136 \pm 18$ & $868 \pm 2$ \\
\hline Set 2 & $770 \pm 22$ & $494 \pm 74$ & $891 \pm 3$ & $550 \pm 8$ & $929 \pm 4$ & $550 \pm 4$ \\
\hline Set 4 & GD15 & GD15 & GD15 & GD15 & Autoclaved & GD15 & Autoclaved \\
\hline Set 1 & ND & ND & $1444 \pm 11$ & $357 \pm 17$ & $1836 \pm 9$ & $386 \pm 15$ \\
\hline Set 2 & ND & ND & $985 \pm 90$ & $286 \pm 21$ & $1592 \pm 30$ & $334 \pm 4$ \\
\hline Set 4 & ND & ND & $785 \pm 3$ & $339 \pm 3$ & $1349 \pm 15$ & $450 \pm 7$ \\
\hline
\end{tabular}


A

E. coli $15 \min C T$

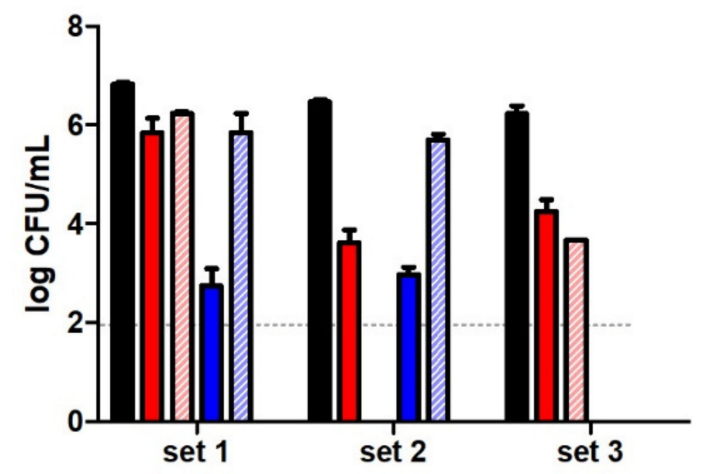

C E. coli $30 \mathrm{~min} \mathrm{CT}$

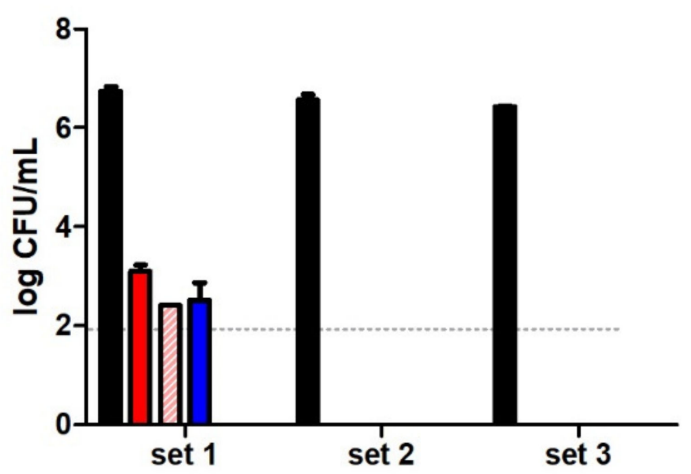

E E. coli $60 \min \mathrm{CT}$

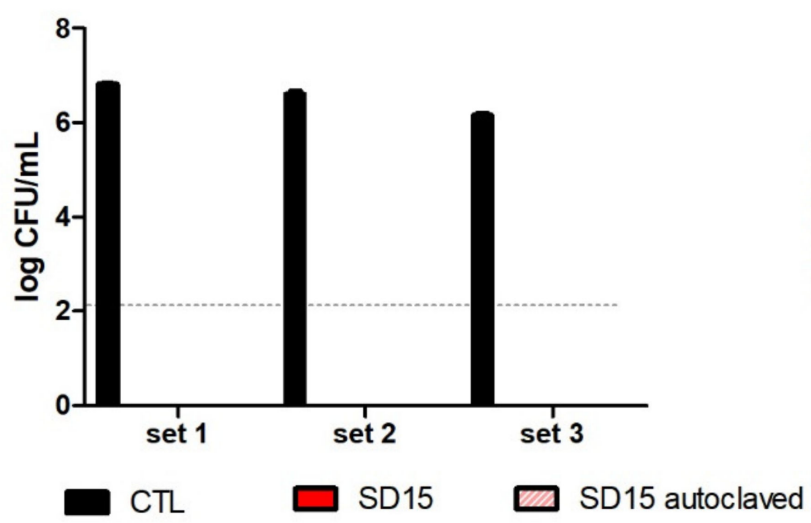

B

S. aureus $15 \mathrm{~min} C T$

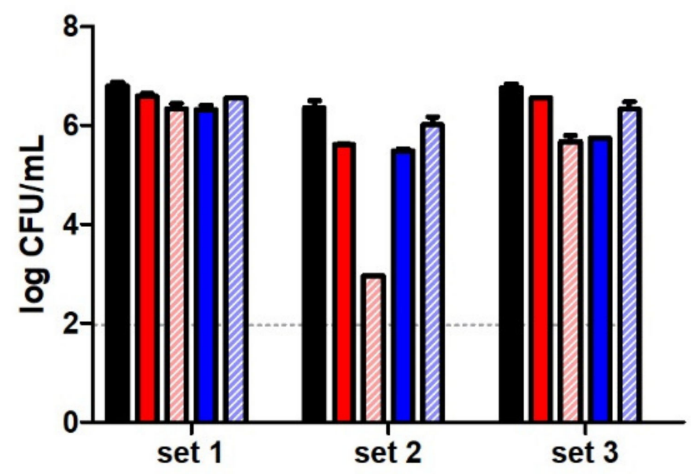

D

S. aureus $30 \mathrm{~min} C \mathrm{CT}$

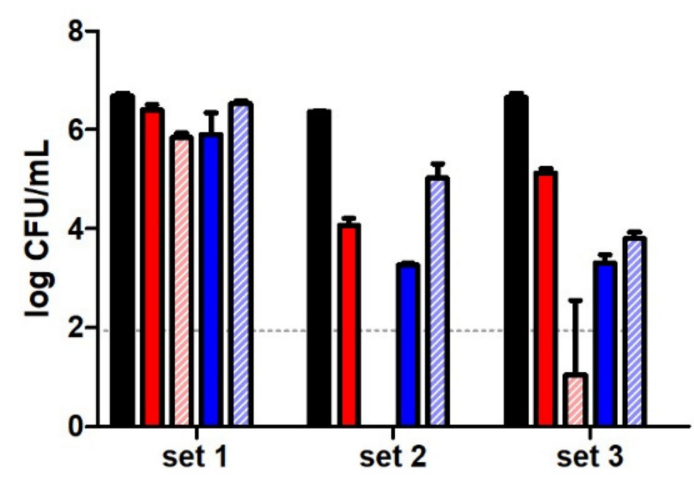

F S. aureus $60 \mathrm{~min} C T$

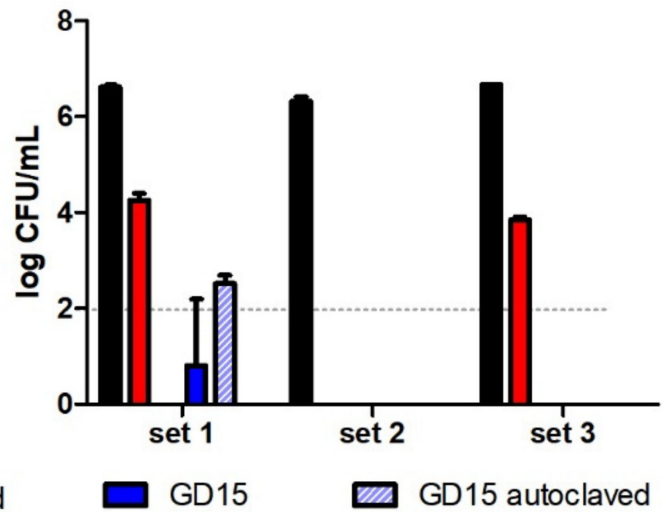

Figure 6. Effect of autoclaving on retention of antimicrobial activity of SD15 and GD15 PAW over 15-60 min contact time (CT). (A) E. coli-15 min; (B) S. aureus-15 $\mathrm{min}$; (C) E. coli-30 $\mathrm{min}$; (D) S. aureus-30 $\mathrm{min}$; (E) E. coli-60 min; (F) S. aureus $-60 \mathrm{~min}$ (data shown as mean $\pm \mathrm{SD}$ ). Limit of detection: $2 \log _{10} \mathrm{CFU} / \mathrm{mL}$. 
A

CHO-K1

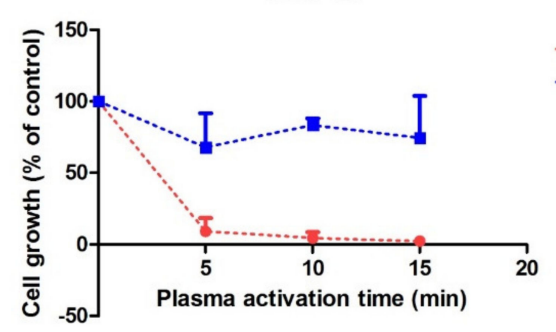

B

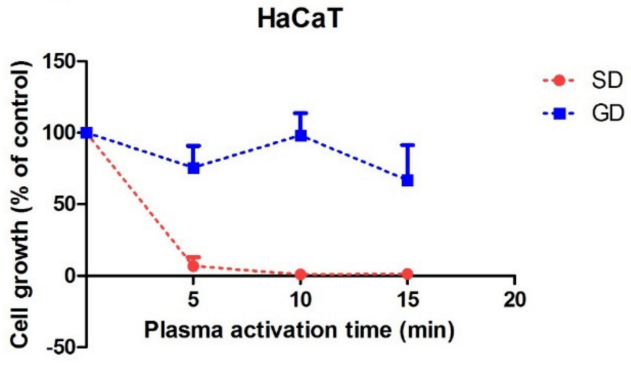

Figure 7. Cell growth of CHO-K1 (A) and HaCaT (B) cell lines exposed to PAW generated by SD and GD discharge at $20 \%$ $(v / v)$ as plasma activation time of PAW increases (data shown as mean $\pm \mathrm{SD}, n=3$ ).

\subsection{Effect on Enzyme Activity}

The biological targets for plasma reactive species are diverse and it has been shown both in a cellular context and in isolation that exposure to these species can lead to lipid peroxidation, protein modification, and changes to enzymatic activity. Lactate dehydrogenase (LDH) is found in most mammalian and bacterial cells and has been used as a model to study the effects of plasma treatment on enzyme function.

The same samples of plasma activated water studied above were tested for their effect on the enzyme LDH. All three sets tested showed a strong reduction of enzymatic activity by SD PAW for all plasma activation times. However, incubation with GD PAW resulted in similar or slightly enhanced enzyme activity compared to the control as observed in the time course of enzymatic NADH generation (Figure 8A-C) and the calculated LDH activity (Figure 8D). The three experimental sets were tested simultaneously and indicated similar effects of specific PAW activation times on LDH activities, even though the sets were of different age between 1 day and 2 weeks after generation.

A

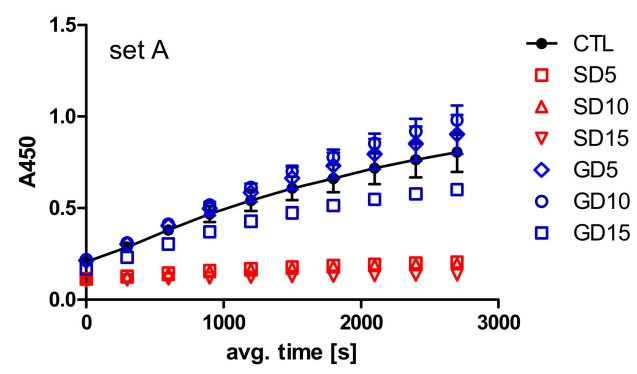

C

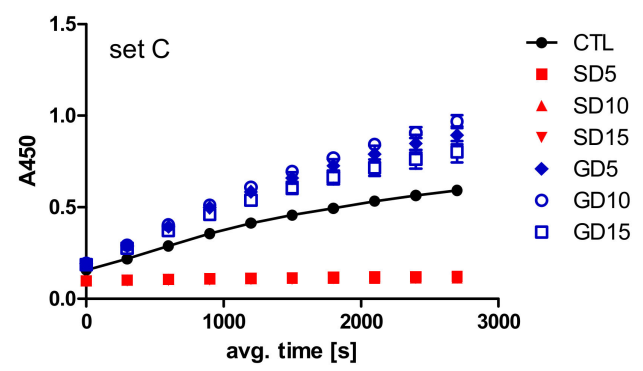

B

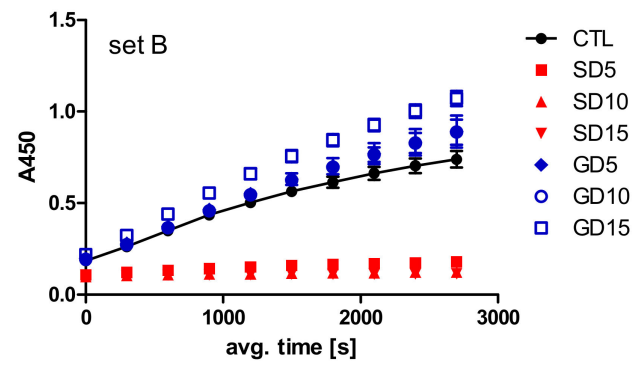

D

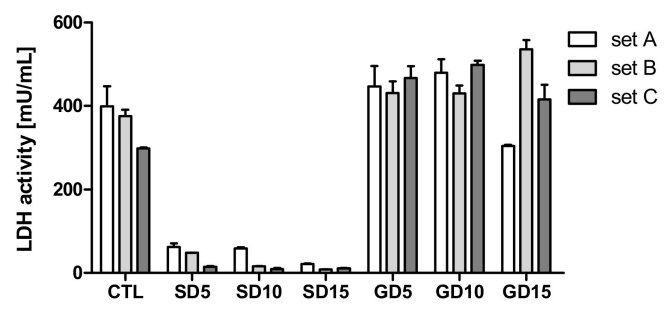

Figure 8. Effect of SD and GD PAW and their activation times on the enzymatic activity of lactate dehydrogenase (LDH); absorbance at A450 indicates reduction of NAD to NADH. Graphs show the results of three sets of PAW, generated at different time points but tested simultaneously. (A) Set A 2 weeks after generation; (B) set B 1 week after generation; (C) set C 1 day after PAW generation; (D) average LDH activity for all sets (data shown as mean \pm SD). 


\section{Discussion}

Different discharge modes above liquids can realise reactive chemical species specificity. The impact of PAW on the reduction of bacterial and mammalian growth depends on its chemical composition. The bactericidal effects of PAW generated by SD and GD revealed that both of these PAW were more effective against E. coli than S. aureus. Grampositive bacteria have been reported to be more resistant than Gram-negative bacteria when exposed directly to plasma discharges [26,27]. Comparing SD and GD PAW, for the same plasma activation times, GD PAW caused higher microbial inactivation, with spark discharge resulting in generation of hydrogen peroxide and nitrate in PAW, whereas glow discharge contained nitrite, nitrate, and other oxidative species. In the present work, the bactericidal effects are attributed to nitrites, nitrates, ROS, and acidic $\mathrm{pH}$ for PAW made by glow discharge. Regarding SD PAW, high concentrations of hydrogen peroxide and nitrates, and acidic $\mathrm{pH}$ are the main chemical species to inactivate bacteria. The existence of other chemical species, both short and long lived, in PAW and their role in bactericidal effects should not be excluded.

Synergistic effects of ROS and RNS are important for bactericidal activity [16] and the chemical composition of PAW influences its antimicrobial efficacy in different ways. Studies on the bactericidal effects of PAW on Gram-negative cells showed that nitrates, nitrites, and $\mathrm{H}_{2} \mathrm{O}_{2}$ in acidic solution can lead to lethal activity [3]. PAW caused damage to the outer and cytoplasmic membrane of Pseudomonas, which was accompanied by leakage of intracellular components such as nucleic acids and proteins. Plasma-induced chemical species can cause bacterial death through inhibition of the antioxidant machinery, which disrupts the membrane protein repair chaperone mechanism, and also DNA repair cascade [28]. Interaction between nitrite, nitrate, and hydrogen peroxide generated in PAL, showed strong antibacterial effects against E. coli [29]. In our study, E. coli was reduced by up to $6 \log$ which was attributed to effects of both ROS and RNS and/or potential synergies between reactive species, by using either of the setups. Therefore, the plasma-induced effects on living organisms are likely to be caused by several agents with multiple targets which possibly lead to synergistic inactivation effects. Further studies are required to better understand the bactericidal inactivation mechanisms of PAW.

Peroxynitrite concentration in PAW was reported to have a crucial role in the microbial inactivation of $E$. coli, where despite the short half-life, this was sufficient to diffuse into cells and lead to bactericidal effects $[17,30]$. In our study this conclusion could corelate with PAW made by glow discharge, which was more efficient than SD PAW and lacked hydrogen peroxide, whereas measurements with potassium iodide indicated high concentrations of ROS which could be peroxynitrite. According to Oehmigen et al. peroxynitrite or peroxynitrous acid as transient products could be formed at some stage of the chemical reactions in the liquid phase [31]. With regards to Gram-positive bacteria, simulation studies have shown that plasma generated chemical species such as hydrogen peroxide, atomic oxygen, and hydroxyl radicals can interact with the bacterial peptidoglycan of S. aureus and lead to breakage of bonds of peptidoglycan of the cell wall, and result in its destruction [32].

Bactericidal solutions to be used as antiseptics should possess a potent activity and a long-lasting effect. According to Traylor et al., $20 \mathrm{~min}$ PAW, generated by a surface micro-discharge plasma system in air, retained its antibacterial activity for 7 days [33]. Our study is in accordance with these results as we reported that SD PAW and GD PAW plasma treated for $15 \mathrm{~min}$, retained their antimicrobial activity after 1 week of storage at $4{ }^{\circ} \mathrm{C}$, thus making PAW a candidate for biomedical use. Plasma treatment of a liquid can cause acidification of solution [31,33]. Decrease of $\mathrm{pH}$ can occur due to presence of nitrogen oxides, which can be produced from atmospheric air by the plasma and dissolve in liquids [31]. In our study, $\mathrm{pH}$ decreased with increasing plasma exposure time of deionised water and this result is in accordance with other reports [5,6,31] and remained stable for at least a week. Concentrations of some of the chemical species were altered in the same storage period, indicating that the chemical reactive species in PAW may have 
reacted to form other secondary products, with $\mathrm{pH}$ and conductivity values remaining the same. Antimicrobial effects of PAW can persist for days but artificially prepared solutions mimicking chemistry of PAW were shown to be less effective [33]. According to Lukes et al., post-discharge reactions between nitrites and hydrogen peroxide can occur in PAW and result in formation of peroxynitrite [34] and nitrate [35].

PAW has the potential to be formulated for use in a variety of clinical applications, such as disinfection, blood coagulation, oncotherapy, or wound healing. Formulations used in clinical settings or as carriers for therapeutics normally undergo terminal sterilisation, which may be mediated by heat and pressure. The PAW generated here has the potential to be used in a setting requiring sterilisation but might undergo chemical decomposition through a number of pathways at the elevated temperatures used for its sterilisation. A widely used method for sterilisation is moist heat in the form of saturated steam under pressure. The basic principle of steam sterilisation, as accomplished in an autoclave, is to expose each item to direct steam contact at high temperature and pressure for a specific time. Thus, there are four parameters of steam sterilisation: steam, pressure, temperature, and time.

In this study different temperatures and heating times were applied to PAW, and results showed that this PAW retains antimicrobial efficacy. In some cases, autoclaving actually increased the antimicrobial efficacy by comparison with unheated PAW. From a reactive species point of view, hydrogen peroxide and peroxides of SD15 PAW were strongly reduced post autoclaving. Reduction of peroxides post autoclaving was also observed for GD15 PAW, which also retained antimicrobial effects at longer contact times. This suggests that other chemical species were primarily responsible for the bactericidal effects of PAW. The differences in the concentrations and/or structure of chemical species measured in this study could be caused by autoclave sterilisation because of the high pressure and steam. Moreover, stability of hydrogen peroxide can be altered by increase of temperature [36] and result in its decomposition to yield oxygen and water. In conclusion, these results show that PAW can be generated to provide strong disinfectant efficacy and retain its stability in different conditions, including high temperatures and pressure. In addition, the possibility of post-plasma modifications of plasma activated liquids to alter their chemical composition and biological effects arises and presents an exciting avenue for further investigations.

Antimicrobial stability of PAW to heat and pressure broadens the application potential of this technology. Autoclaved PAW can provide a valuable decontamination tool for the removal of bacteria in many settings, including hospitals and other health care institutions. It can be used for example as a "no-touch" (automated) decontamination method using vaporised plasma activated water for reduction of microbial contamination of surfaces. Another example for autoclaved PAW application is thermal fogging. Thermal fogging disinfection can be used in livestock industry and medical setting, for decontamination of surfaces and aerosols in the air. In both examples, PAW could be added as a disinfectant in these devices, heated at desired temperature in order to generate fog $/$ mist and then used in a contaminated area. Clean-in-place and steam-in-place processes are furthermore commonly used in pharmaceutical and food processing industries, where plasma activated liquids could find use for sanitisation applications.

Cytotoxicity results demonstrated that GD PAW had a better safety profile than SD PAW; using the same plasma activation times, a significantly higher cytotoxicity was observed by SD PAW for both cell lines. Hydrogen peroxide in SD PAW seems to be a central player in this process, but a role of nitrite and nitrate concentration or other reactive species (GD PAW) in cytotoxicity cannot be excluded as GD PAW showed growth inhibition in the absence of hydrogen peroxide. Several publications have reported hydrogen peroxide as a principle cytotoxic reactive species in PAL. Reduction of cell growth and viability of $\mathrm{CHO}-\mathrm{K} 1$ and HaCaT cells showed a linear correlation to the concentration of peroxide in PAL in previous studies [19,37]. Moreover, Lu et al. investigated the cytotoxic effects of SD PAW combined with GD PAW and observed that cytotoxicity was reduced by GD 
treatment in line with the reductions of hydrogen peroxide concentrations [37]. In the same study, PAW containing only nitrates of approximately $1.5 \mathrm{mM}$ showed minor cytotoxicity, suggesting that nitrite could play a role in cell death attributed to GD PAW, even though the addition of nitrite and nitrate concentrations up to $1.2 \mathrm{mM}$ showed no cytotoxic effects on HeLa cells in another investigation [25].

Other chemical reactive species, including less stable transient species, may also be responsible for inhibition of cell growth. Peroxynitrous acid can be formed by the interaction of nitrites and hydrogen peroxide, in weakly acidic to acid solutions [21]. The plasma treatment of water led to a decrease of $\mathrm{pH}$, generating an acidic environment, which can promote peroxynitrous acid formation. Peroxynitrite/peroxynitrous acid can cause cell death by inducing both cellular apoptosis and necrosis [23].

Similar to the effects on mammalian cells, the impact of PAW on enzyme activity of lactate dehydrogenase appears to be dominated by hydrogen peroxide. Studies by $\mathrm{Xu}$ et al. on plasma treated LDH suggested a role for long-lived species such as hydrogen peroxide and nitrate in changing the protein's secondary structure and activity [38]. Plasma reactive species can lead to modifications of protein secondary and tertiary structure [39] and induce changes to amino acids through reactions such as hydroxylation, nitration, or oxidation [40]. Solutions containing only nitrate and nitrite in our investigations not only retained enzymatic activity but even led to slight increases, suggesting that PAW could induce conformational changes which may not be detrimental to enzyme functionality. Studies conducted with the same plasma set-up on milk proteins found an increased affinity of $\beta$-lactoglobulin to an anti- $\beta$-lactoglobulin antibody after direct treatment with both SD and GD plasma discharge while antibody affinity of other milk proteins was reduced [41], indicating that plasma reactive species can affect different proteins in diverse ways.

\section{Conclusions}

In this study, the biological effects and the influence of heating temperature on the bactericidal effects of PAW generated by two different discharges were investigated. We established that PAW solutions may be suitable disinfectant solutions in terms of potent and stable bactericidal efficacy as well as biological safety to nontarget cells. Investigation of the chemical composition of two types of PAW, showed that PAW consisted of different long-lived chemical species. PAW were able to retain their bactericidal effects against both Gram-positive and Gram-negative bacteria post generation for up to 1 week at refrigerated temperature. PAW heated for varying times showed that PAW could retain its bactericidal activity on both $E$. coli and S. aureus even when it had been autoclaved. A better understanding of the mechanisms of the biological activity of PAW will lead to an improved classification and more targeted applications and may provide post-plasma modifications as further means of modulating the chemistry and biological effects of these liquids.

Author Contributions: Conceptualisation, E.T., D.B., P.B.; methodology, E.T., D.B.; software, E.T., D.B.; validation, E.T., D.B.; formal analysis, E.T., D.B.; investigation, E.T., D.B., M.D., L.T.; resources, D.B., P.B.; data curation, D.B.; writing-original draft preparation, E.T.; writing-review and editing, E.T., D.B., P.B.; visualisation, E.T., D.B.; supervision, D.B.; P.B.; project administration, D.B., P.B.; funding acquisition, D.B., P.B. All authors have read and agreed to the published version of the manuscript.

Funding: This research was funded by Science Foundation Ireland, under grant numbers 15/SIRG/3466, 16/BBSRC/3391 and 20/US/3678.

Informed Consent Statement: Not applicable.

Data Availability Statement: The data presented in this study are available on request from the corresponding author.

Acknowledgments: The CHO-K1 cell line was kindly provided by Professor Mohamed Al-Rubeai (School of Chemical and Bioprocess Engineering, UCD, Dublin, Ireland) and the HaCaT cells were obtained from Professor Fiona Lyng (Radiation and Environmental Science Centre, Technological University Dublin). 
Conflicts of Interest: The authors declare no conflict of interest.

\section{References}

1. Jablonowski, H.; von Woedtke, T. Research on plasma medicine-relevant plasma-liquid interaction: What happened in the past five years? Clin. Plasma Med. 2015, 3, 45-52. [CrossRef]

2. Bruggeman, P.J.; Kushner, M.J.; Locke, B.R.E.; Gardeniers, J.G.; Graham, W.G.; Graves, D.B.; Hofman-Caris, R.C.H.M.; Maric, D.; Reid, J.P.; Ceriani, E.; et al. Plasma-liquid interactions: A review and roadmap. Plasma Sources Sci. Technol. 2016, $25,053002$. [CrossRef]

3. Shen, J.; Tian, Y.; Li, Y.; Ma, R.; Zhang, Q.; Zhang, J.; Fang, J. Bactericidal Effects against S. aureus and Physicochemical Properties of Plasma Activated Water stored at different temperatures. Sci. Rep. 2016, 6, 28505. [CrossRef] [PubMed]

4. Kaushik, N.K.; Ghimire, B.; Li, Y.; Adhikari, M.; Veerana, M.; Kaushik, N.; Jha, N.; Adhikari, B.; Lee, S.-J.; Masur, K.; et al. Biological and medical applications of plasma-activated media, water and solutions. Biol. Chem. 2018, 400, 39-62. [CrossRef] [PubMed]

5. Tsoukou, E.; Bourke, P.; Boehm, D. Understanding the Differences Between Antimicrobial and Cytotoxic Properties of Plasma Activated Liquids. Plasma Med. 2018, 8, 299-320. [CrossRef]

6. Tsoukou, E.; Bourke, P.; Boehm, D. Temperature Stability and Effectiveness of Plasma-Activated Liquids over an 18 Months Period. Water 2020, 12, 3021. [CrossRef]

7. Dancer, S.J. Controlling Hospital-Acquired Infection: Focus on the Role of the Environment and New Technologies for Decontamination. Clin. Microbiol. Rev. 2014, 27, 665-690. [CrossRef]

8. Inguglia, E.S.; Oliveira, M.; Burgess, C.M.; Kerry, J.P.; Tiwari, B. Plasma-activated water as an alternative nitrite source for the curing of beef jerky: Influence on quality and inactivation of Listeria innocua. Innov. Food Sci. Emerg. Technol. 2020, 59 , 102276. [CrossRef]

9. Frías, E.; Iglesias, Y.; Alvarez-Ordóñez, A.; Prieto, M.; González-Raurich, M.; López, M. Evaluation of Cold Atmospheric Pressure Plasma (CAPP) and plasma-activated water (PAW) as alternative non-thermal decontamination technologies for tofu: Impact on microbiological, sensorial and functional quality attributes. Food Res. Int. 2020, 129, 108859. [CrossRef]

10. Su, X.; Tian, Y.; Zhou, H.; Li, Y.; Zhang, Z.; Jiang, B.; Yang, B.; Zhang, J.; Fang, J. Inactivation Efficacy of Nonthermal PlasmaActivated Solutions against Newcastle Disease Virus. Appl. Environ. Microbiol. 2018, 84. [CrossRef]

11. Patange, A.; Lu, P.; Boehm, D.; Cullen, P.; Bourke, P. Efficacy of cold plasma functionalised water for improving microbiological safety of fresh produce and wash water recycling. Food Microbiol. 2019, 84, 103226. [CrossRef] [PubMed]

12. Balan, G.G.; Rosca, I.; Ursu, E.-L.; Doroftei, F.; Bostănaru, A.-C.; Hnatiuc, E.; Năstasă, V.; Sandru, V.; Stefanescu, G.; Trifan, A.; et al. Plasma-activated water: A new and effective alternative for duodenoscope reprocessing. Infect. Drug Resist. 2018, 11, 727-733. [CrossRef] [PubMed]

13. Li, Y.; Pan, J.; Ye, G.; Zhang, Q.; Wang, J.; Zhang, J.; Fang, J. In Vitro studies of the antimicrobial effect of non-thermal plasmaactivated water as a novel mouthwash. Eur. J. Oral Sci. 2017, 125, 463-470. [CrossRef]

14. Ng, S.W.; Tsoukou, E.; Chaple, S.; Boehm, D.; Bourke, P. Plasma Treatment of Liquids. Innov. Food Process. Technol. 2021, 1, 610-634.

15. Tian, Y.; Ma, R.; Zhang, Q.; Feng, H.; Liang, Y.; Zhang, J.; Fang, J. Assessment of the Physicochemical Properties and Biological Effects of Water Activated by Non-thermal Plasma Above and Beneath the Water Surface. Plasma Process. Polym. 2015, 12, 439-449. [CrossRef]

16. Shaw, P.; Kumar, N.; Kwak, H.S.; Park, J.H.; Uhm, H.S.; Bogaerts, A.; Choi, E.H.; Attri, P. Bacterial inactivation by plasma treated water enhanced by reactive nitrogen species. Sci. Rep. 2018, 8, 1-10. [CrossRef]

17. Zhou, R.; Zhou, R.; Prasad, K.; Fang, Z.; Speight, R.; Bazaka, K.; Ostrikov, K. Cold atmospheric plasma activated water as a prospective disinfectant: The crucial role of peroxynitrite. Green Chem. 2018, 20, 5276-5284. [CrossRef]

18. Hirst, A.M.; Frame, F.M.; Arya, M.; Maitland, N.J.; O'Connell, D. Low temperature plasmas as emerging cancer therapeutics: The state of play and thoughts for the future. Tumor Biol. 2016, 37, 7021-7031. [CrossRef]

19. Boehm, D.; Heslin, C.; Cullen, P.J.; Bourke, P. Cytotoxic and mutagenic potential of solutions exposed to cold atmospheric plasma. Sci. Rep. 2016, 6, 21464. [CrossRef]

20. Girard, P.-M.; Arbabian, A.; Fleury, M.; Bauville, G.; Puech, V.; Dutreix, M.; Sousa, J.S. Synergistic Effect of $\mathrm{H}_{2} \mathrm{O}_{2}$ and $\mathrm{NO}_{2}$ in Cell Death Induced by Cold Atmospheric He Plasma. Sci. Rep. 2016, 6, 29098. [CrossRef]

21. Brisset, J.-L.; Pawlat, J. Chemical Effects of Air Plasma Species on Aqueous Solutes in Direct and Delayed Exposure Modes: Discharge, Post-discharge and Plasma Activated Water. Plasma Chem. Plasma Process. 2016, 36, 355-381. [CrossRef]

22. Starodubtseva, M.N.; Cherenkevich, S.N.; Semenkova, G.N. Investigation of the interaction of sodium nitrite with hydrogen peroxide in aqueous solutions by the chemiluminescence method. J. Appl. Spectrosc. 1999, 66, 473-476. [CrossRef]

23. Szabo, C.; Ischiropoulos, H.; Radi, R. Peroxynitrite: Biochemistry, pathophysiology and development of therapeutics. Nat. Rev. Drug Discov. 2007, 6, 662-680. [CrossRef]

24. Lu, P.; Boehm, D.; Bourke, P.; Cullen, P.J. Achieving reactive species specificity within plasma-activated water through selective generation using air spark and glow discharges. Plasma Process. Polym. 2017, 14. [CrossRef]

25. Boehm, D.; Curtin, J.; Cullen, P.; Bourke, P. Hydrogen Peroxide and Beyond-the Potential of High-voltage Plasma-activated Liquids Against Cancerous Cells. Anti Cancer Agents Med. Chem. 2018, 18, 815-823. [CrossRef] 
26. Ermolaeva, S.A.; Varfolomeev, A.F.; Chernukha, M.Y.; Yurov, D.S.; Vasiliev, M.M.; Kaminskaya, A.A.; Moisenovich, M.M.; Romanova, J.M.; Murashev, A.N.; Selezneva, I.I.; et al. Bactericidal effects of non-thermal argon plasma in vitro, in biofilms and in the animal model of infected wounds. J. Med. Microbiol. 2011, 60, 75-83. [CrossRef]

27. Lee, K.; Paek, K.-H.; Ju, W.-T.; Lee, Y. Sterilization of bacteria, yeast, and bacterial endospores by atmospheric-pressure cold plasma using helium and oxygen. J. Microbiol. 2006, 44, 269-275.

28. Vatansever, F.; De Melo, W.C.; Avci, P.; Vecchio, D.; Sadasivam, M.; Gupta, A.; Chandran, R.; Karimi, M.; Parizotto, N.A.; Yin, R.; et al. Antimicrobial strategies centered around reactive oxygen species-bactericidal antibiotics, photodynamic therapy, and beyond. FEMS Microbiol. Rev. 2013, 37, 955-989. [CrossRef]

29. Hänsch, M.A.C.; Mann, M.; Weltmann, K.-D.; Von Woedtke, T. Analysis of antibacterial efficacy of plasma-treated sodium chloride solutions. J. Phys. D Appl. Phys. 2015, 48, 454001. [CrossRef]

30. Lukes, P.; Locke, B.R.; Brisset, J.L. Aqueous-Phase Chemistry of Electrical Discharge Plasma in Water and in Gas-Liquid Environments. In Plasma Chemistry and Catalysis in Gases and Liquids, 1st ed.; Parvulescu, V.I., Magureanu, M., Lukes, P., Eds.; Wiley: Hoboken, NJ, USA, 2012; pp. 243-308.

31. Oehmigen, K.; Winter, J.; Hähnel, M.; Wilke, C.; Brandenburg, R.; Weltmann, K.-D.; Von Woedtke, T. Estimation of Possible Mechanisms of Escherichia coli Inactivation by Plasma Treated Sodium Chloride Solution. Plasma Process. Polym. 2011, 8, 904-913. [CrossRef]

32. Yusupov, M.; Bogaerts, A.; Huygh, S.; Snoeckx, R.; Van Duin, A.C.T.; Neyts, E.C. Plasma-Induced Destruction of Bacterial Cell Wall Components: A Reactive Molecular Dynamics Simulation. J. Phys. Chem. C 2013, 117, 5993-5998. [CrossRef]

33. Traylor, M.J.; Pavlovich, M.J.; Karim, S.; Hait, P.; Sakiyama, Y.; Clark, D.S.; Graves, D.B. Long-term antibacterial efficacy of air plasma-activated water. J. Phys. D Appl. Phys. 2011, 44, 472001. [CrossRef]

34. Lukes, P.; Dolezalova, E.; Sisrova, I.; Clupek, M. Aqueous-phase chemistry and bactericidal effects from an air discharge plasma in contact with water: Evidence for the formation of peroxynitrite through a pseudo-second-order post-discharge re-action of $\mathrm{H}_{2} \mathrm{O}_{2}$ and $\mathrm{HNO}_{2}$. Plasma Sources Sci. Technol. 2014, 23, 015019. [CrossRef]

35. Burlica, R.; Grim, R.G.; Shih, K.-Y.; Balkwill, D.; Locke, B.R. Bacteria Inactivation Using Low Power Pulsed Gliding Arc Dis-charges with Water Spray. Plasma Process. Polym. 2010, 7, 640-649. [CrossRef]

36. Yazici, E.Y.; Deveci, H. Factors effecting decomposition of hydrogen peroxide. In Proceedings of the XIIth Interna-Tional Mineral Processing Symposium, Cappadoccia-Neveshir, Turkey, 6-8 October 2010; pp. 609-616.

37. Lu, P.; Boehm, D.; Cullen, P.; Bourke, P. Controlled cytotoxicity of plasma treated water formulated by open-air hybrid mode discharge. Appl. Phys. Lett. 2017, 110, 264102. [CrossRef]

38. Zhang, Z.; Xu, Z.; Shen, J.; Li, X.; Ding, L.; Ma, J.; Lan, Y.; Xia, W.; Cheng, C.; Sun, Q.; et al. Effects and Mechanism of Atmospheric-Pressure Dielectric Barrier Discharge Cold Plasma on Lactate Dehydrogenase (LDH) Enzyme. Sci. Rep. 2015, 5, 10031. [CrossRef]

39. Park, J.H.; Kim, M.; Shiratani, M.; Cho, A.E.; Choi, E.A.; Attri, P. Variation in structure of proteins by adjusting reactive oxy-gen and nitrogen species generated from dielectric barrier discharge jet. Sci. Rep. 2016, 6, 35883. [CrossRef]

40. Takai, E.; Kitamura, T.; Kuwabara, J.; Ikawa, S.; Yoshizawa, S.; Shiraki, K.; Kawasaki, H.; Arakawa, R.; Kitano, K. Chemical modification of amino acids by atmospheric-pressure cold plasma in aqueous solution. J. Phys. D Appl. Phys. 2014, $47,285403$. [CrossRef]

41. Ng, S.W.; Lu, P.; Rulikowska, A.; Boehm, D.; O'Neill, G.; Bourke, P. The effect of atmospheric cold plasma treatment on the antigenic properties of bovine milk casein and whey proteins. Food Chem. 2020, 128283. [CrossRef] 